\title{
KETERDAPATAN EMAS YANG BERASOSIASI DENGAN \\ SINABAR DI KABUPATEN BOMBANA, PROVINSI SULAWESI TENGGARA
}

\author{
Oleh: \\ Kisman \\ Pusat Sumber Daya Geologi \\ Jalan Soekarno Hatta No. 444 Bandung
}

SARI

Kegiatan prospeksi dilakukan untuk mengetahui tipe genesa emas di daerah Kecamatan Rarowatu dan Kecamatan Rarowatu Utara, Kabupaten Bombana, dengan metode pemercontoan geokimia dan konsentrat mineral berat serta analisis mineralogi butir pada 73 conto konsentrat dulang. Hasil penyelidikan menunjukan bahwa di daerah ini terdapat 2 tipe genesa emas yaitu emas primer pada satuan batuan sekis dan emas sekunder pada satuan aluvial yang berasosiasi dengan sinabar.

Kata kunci: genesa emas, konsentrat dulang, sinabar, prospeksi, sekis, aluvial.

\section{ABSTRACT}

Prospecting activities was conducted to determine the type of gold deposits in Rarowatu District, Bombana Regency with geochemical and heavy mineral concentrates sampling methods and grain mineralogical analysis of 73 samples of pan concentrate. Two types of deposit are primary gold occure in schist unit and secondary gold in the alluvium unit associated with cinnabar.

Keywords: gold genesis, pan consentrate, cinabar, prospection, schist, alluvial

\section{PENDAHULUAN}

Merebaknya pendulangan emas oleh masyarakat terjadi di daerah aliran sungai Tahi Ite, Kabupaten Bombana, Sulawesi Tenggara pada pertengahan tahun 2008. Pendulangan emas diawali oleh salah seorang penduduk setempat yang sudah berpengalaman mendulang di daerah Papua. Pada perkembangannya kegiatan pendulangan yang terlibat tidak hanya masyarakat setempat namun juga dari luar Kabupaten Bombana bahkan dari luar Pulau Sulawesi (Dinas Pertambangan dan Energi Kabupaten Bombana, 2008).

Endapan emas di Bombana sebelumnya tidak diketahui keterdapatannya pada eksplorasi geokimia regional bersistem (Bagdja,1998), hal ini dikarenakan unsur Au tidak dianalisis.

Tulisan ini dimaksudkan untuk menganalisis konsentrat sinabar sebagai mineral ikutan emas yang dapat digunakan sebagai mineral petunjuk tipe mineralisasi emas. Lokasi daerah kajian difokuskan di Kecamatan Rarowatu dan Kecamatan Rarowatu Utara, Kabupaten Bombana Provinsi Sulawesi Tenggara (Gambar 1).
Kegiatan penyelidikan ini dilakukan dengan metode pemercontoan konsentrat dulang untuk memperoleh mineral berat pada sungai-sungai orde 1 , orde 2 dan/atau orde 3 . Pengambilan conto konsentrat dulang dilakukan pada permukaan endapan aluvial dengan cara channel sampling, dan sumur-sumur uji dengan volume sekitar 10 liter setiap conto. Pemercontoan batuan juga dilakukan pada batuan sekis teroksidasi di lereng-lereng bukit. Pengujian laboratorium dilakukan berupa analisis mineralogi butir.

Untuk mengetahui berat emas yang terdapat dalam conto konsentrat dari hasil analisis mineralogi butir, digunakan konversi satuan color emas menjadi miligram (Tim Prospeksi, 2009) sebagai berikut :

$\begin{array}{ll}1 \text { VFC (very fine color) } & =0,026 \mathrm{mg} \\ 1 \text { FC (fine color) } & =0,060 \mathrm{mg} \\ 1 \text { MC (medium color) } & =0,3125 \mathrm{mg} \\ 1 \text { CC (coarse color) } & =1,20 \mathrm{mg} \\ 1 \text { VCC (very coarse color) } & =3,52 \mathrm{mg}\end{array}$




\section{MAKALAH ILMIAH}

\section{GEOLOGI DAN MINERALISASI}

Morfologi daerah penyelidikan terdiri dari perbukitan terjal, menempati bagian selatan daerah penyelidikan, perbukitan bergelombang rendah menempati daerah bagian sisi barat, baratlaut hingga agak ke tengah pada daerah penyelidikan. Daerah pedataran menempati bagian utara-timurlaut daerah penyelidikan seperti terlihat pada gambar 2 (Tim Prospeksi, 2009). Pola aliran sungai yang berkembang adalah pola dendritik di bagian utara, seperti percabangan pohon yang mengindikasikan jenis batuan homogen. Di bagian selatan berkembang pola aliran sungai paralel dan sub trelis yang menunjukkan kontrol struktur yang kuat berupa

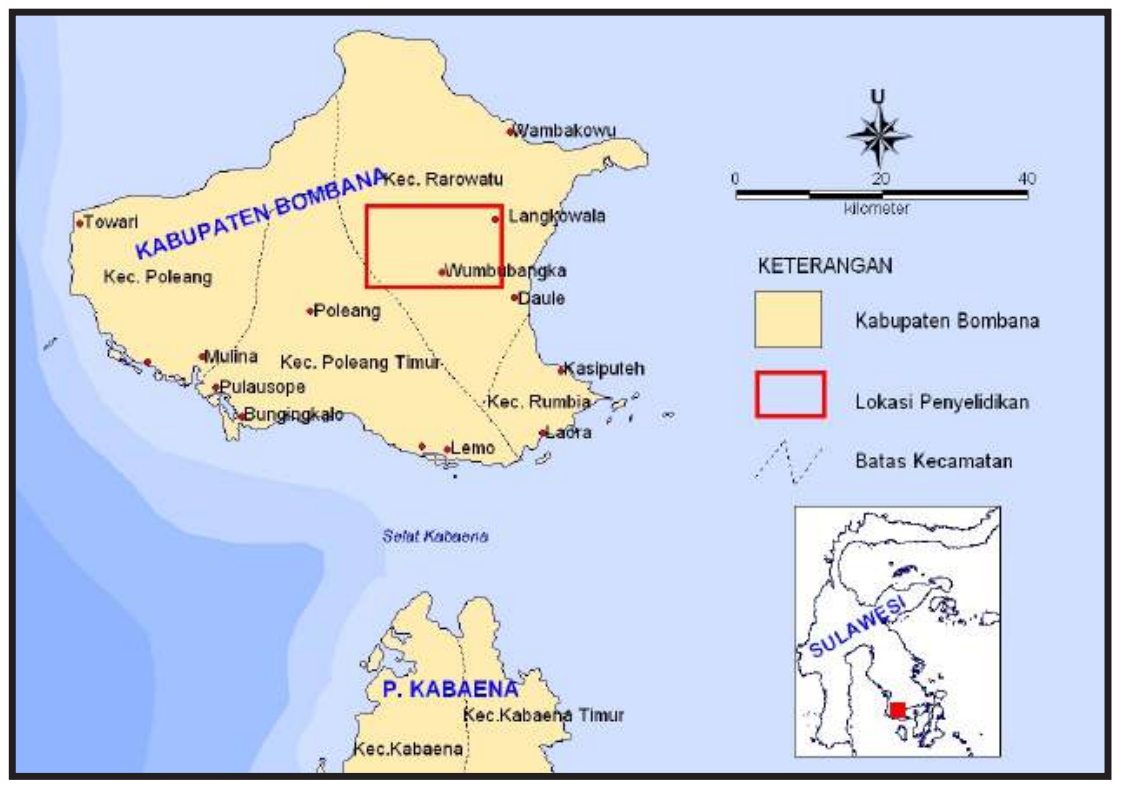

Gambar 1. Peta Lokasi Penyelidikan di Kabupaten Bombana, Provinsi Sulawesi Tenggara

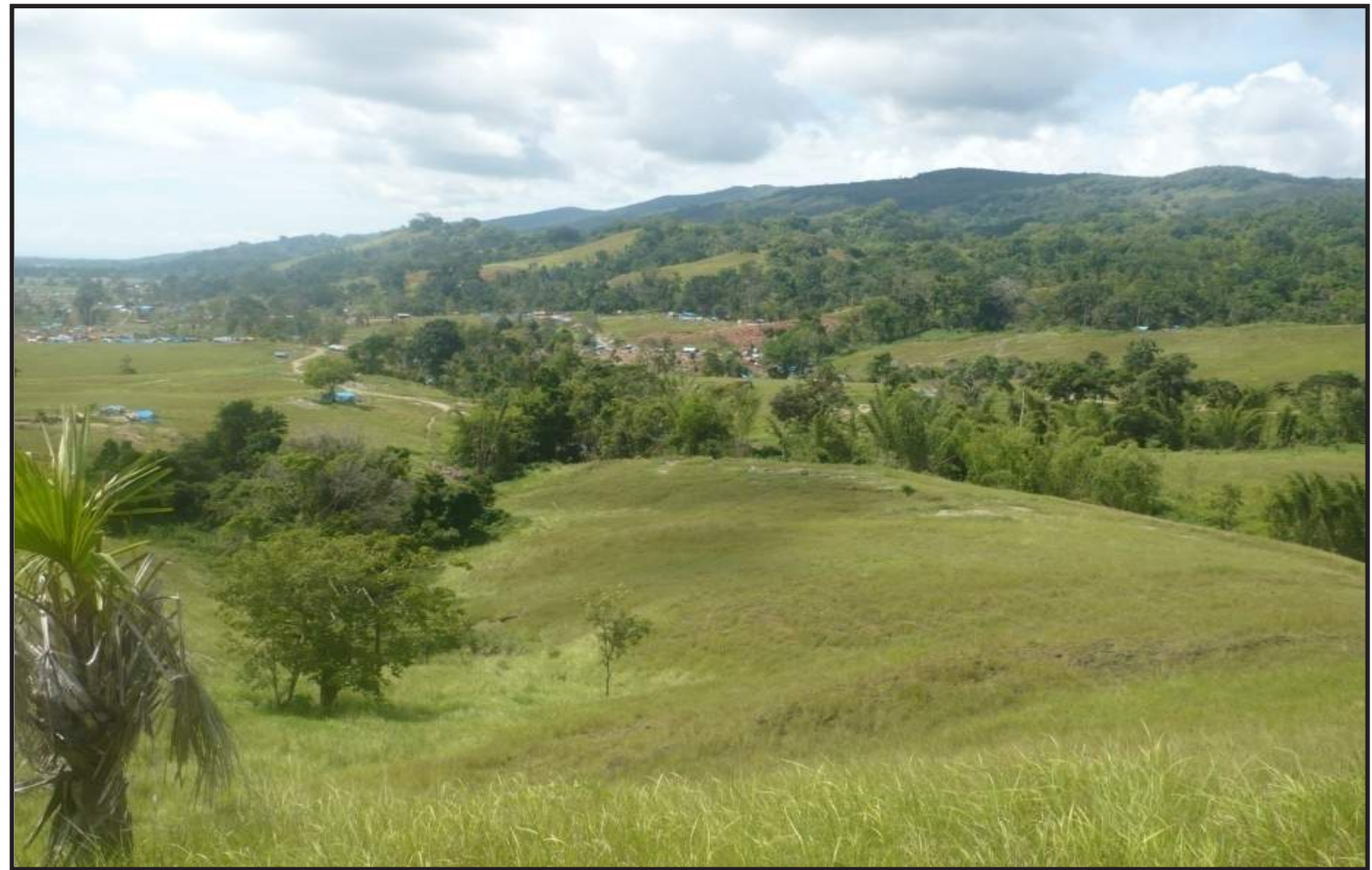

Gambar 2. Morfologi pedataran dan perbukitan bergelombang rendah - terjal di daerah Wumbubangka (Tim Prospeksi, 2009) 


\section{MAKALAH ILMIAH}

sesar dan kekar dengan batuan yang relatif keras.

Stratigrafi daerah penyelidikan tersusun oleh satuan batuan sekis, batupasir konglomeratan, batugamping, dan aluvium (Gambar 3). Sekis terdiri dari sekis mika, sekis klorit dan sekis amfibolit dengan struktur foliasi. Di dalam satuan batuan metamorf ini terdapat bongkahan-bongkahan batuan tersilisifikasi dengan kuarsa bertekstur vuggy mengisi foliasi dan rekahan-rekahan. Umur batuan dari tua ke muda yaitu satuan batugamping berumur Kapur Akhir, satuan batuan sekis berumur KapurPaleosen, satuan sekis teroksidasi dan satuan konglomerat berumur Miosen, sedangkan satuan alluvium berumur Plistosen-Holosen (T.O. Simandjuntak, dkk., 1993).

Struktur geologi utama yang berkembang di daerah penyelidikan berupa sesar normal yang

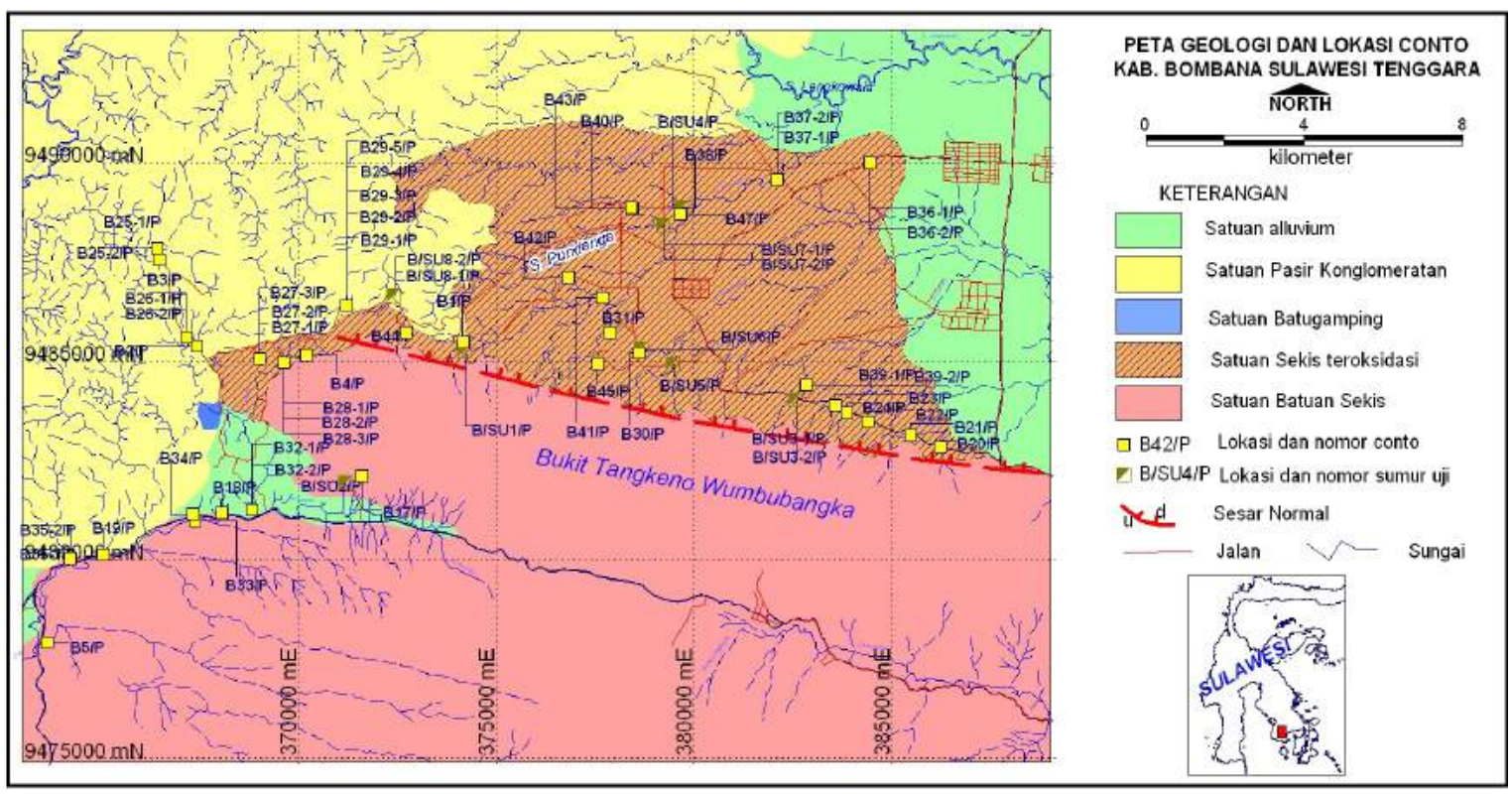

Gambar 3. Peta geologi dan lokasi pengambilan conto daerah penyelidikan (Tim Prospeksi, 2009)

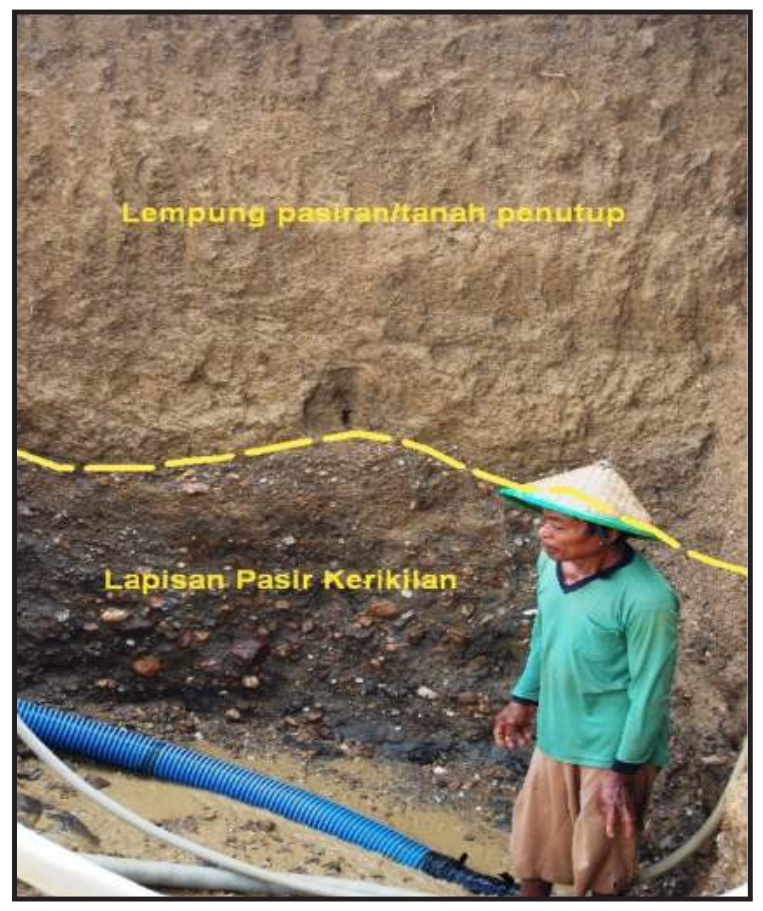

Gambar 4. Penampang endapan aluvial di Sungai Pundanga 


\section{MAKALAH ILMIAH}

memiliki arah umum barat-timur dengan bagian utara merupakan hanging wall yang memisahkan satuan morfologi perbukitan di Bukit Tangkeno Wumbubangka dengan perbukitan rendah dan pedataran di sebelah utara.

Satuan batuan sekis teroksidasi di bagian sayap utara Bukit Tangkeno Wumbubangka diduga merupakan tempat terjadi mineralisasi emas primer. Endapan aluvial berumur Kuarter terdiri dari lumpur, lempung, pasir, kerikil dan kerakal dengan fragmen kuarsa, sekis, rijang dan batupasir merupakan endapan pada alur-alur aliran sungai. Pada endapan aluvial ini terdapat dua lapisan pasir kerikilan sebagai tempat kedudukan emas sekunder yang ditutupi oleh lapisan lempung (Gambar 4).

\section{HASILANALISIS}

Analisis mineralogi butir dilakukan pada 73 conto konsentrat dulang yang diambil dari permukaan dan sumur uji pada endapan aluvial serta batuan sekis teroksidasi, menghasilkan 29 conto yang mengandung butiran emas berukuran sangat halus sampai kasar dengan bentuk pipih sampai membulat tanggung.

Analisis mineralogi butir dilakukan terhadap conto batuan sekis teroksidasi pada conto nomor B42/P di lokasi yang sama dengan conto batuan B13/R (Gambar 5) untuk mengetahui adanya emas pada satuan batuan metamorf. Hasil analisis mineralogi butir conto B42/P terdapat butir emas 3 VFC, 5 MC dan jejak (trace) sinabar. Sedangkan analisis kimia conto B13/R memiliki kadar 12 ppm Cu , 23 ppm Pb , 59 ppm Zn , 19 ppb

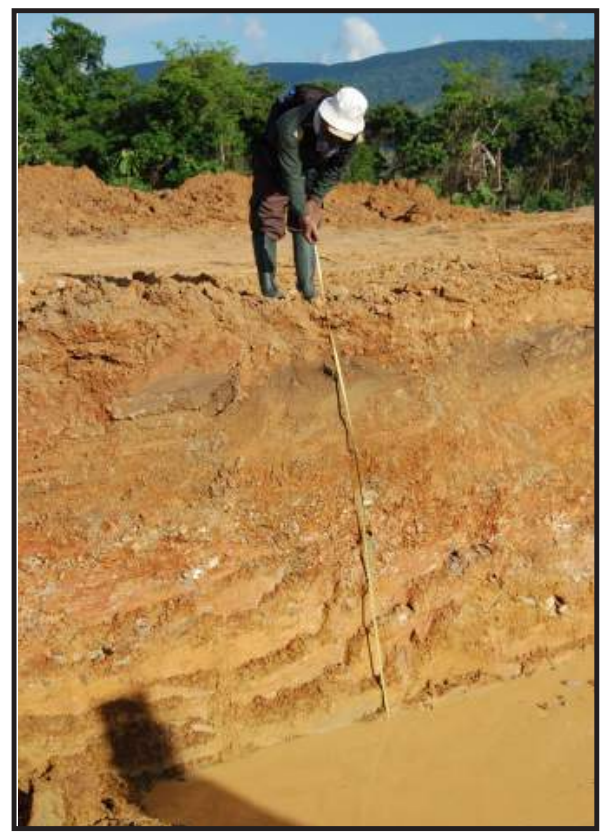

Gambar 5. Batuan sekis teroksidasi conto B42/P dan B13/R

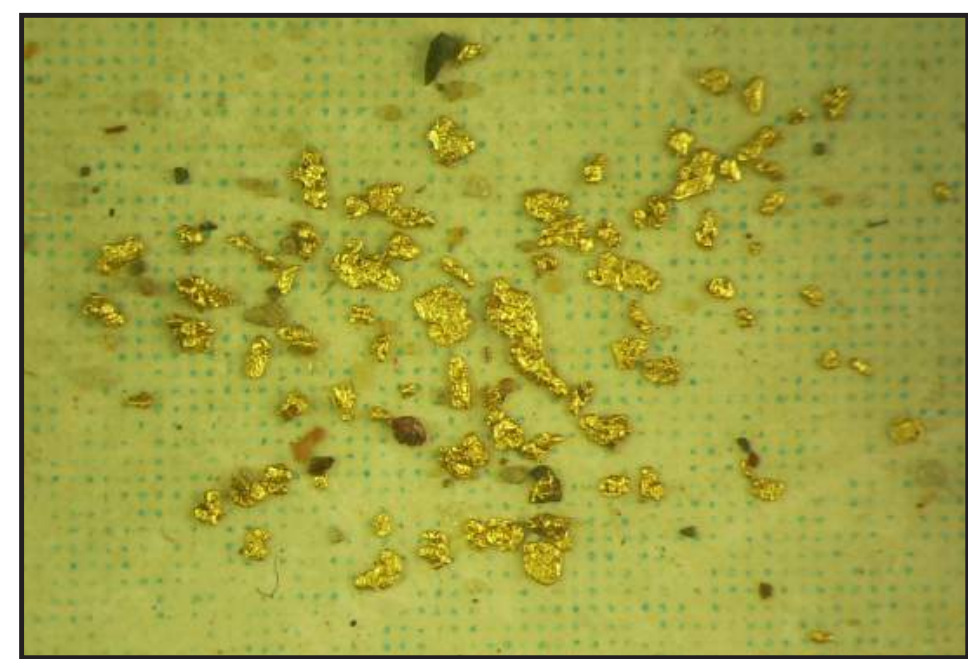

Gambar 6. Fotomikrograf Conto B 37-1/P emas, 20VFC, 22FC, 12MC, 4CC, 1VCC 


\section{MAKALAH ILMIAH}

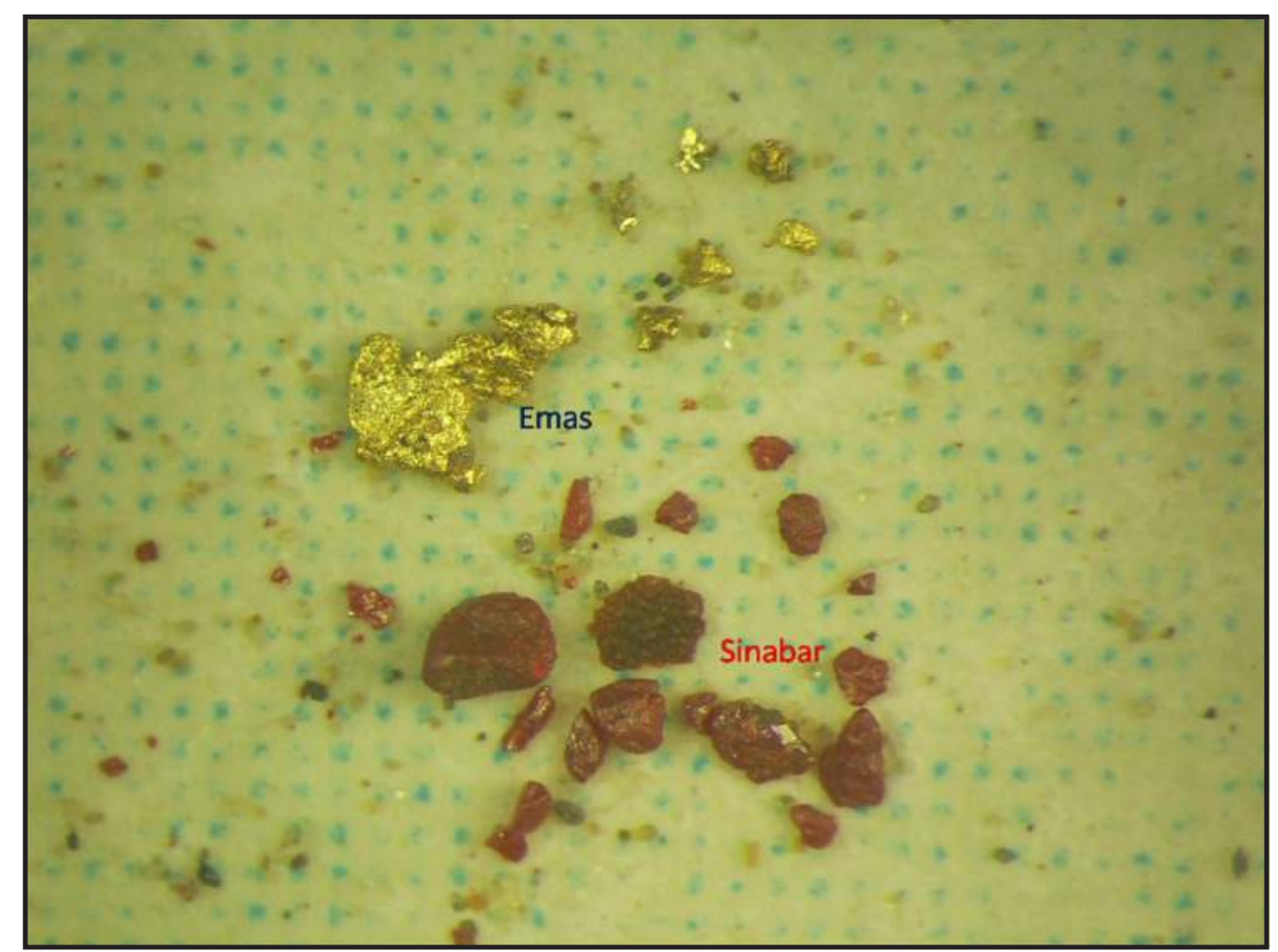

Gambar 7. Fotomikrograf Conto B44/P, sinabar dan emas 6VFC, 1VCC (Tim Prospeksi, 2009)

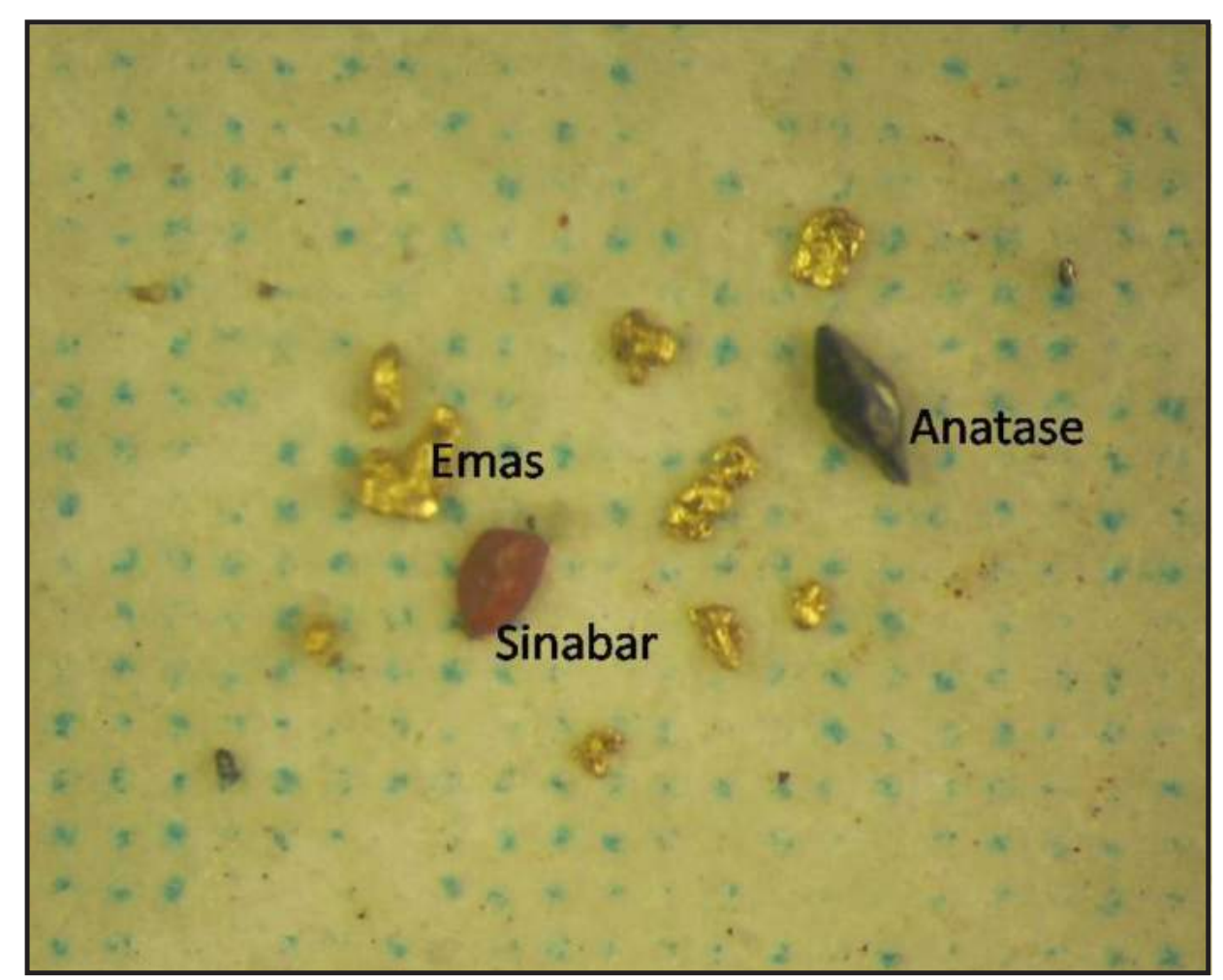

Gambar 8. Fotomikrograf B28-3/P, emas 6VFC, 3FC, anatase dan sinabar 
Tabel 1. Hasil analisis mineralogi butir emas dan sinabar

\begin{tabular}{|c|c|c|c|c|c|}
\hline $\begin{array}{c}\text { NO } \\
\text { URUT }\end{array}$ & $\begin{array}{l}\text { KODE } \\
\text { CONTO }\end{array}$ & $\begin{array}{c}\text { JENIS } \\
\text { MATERIAL }\end{array}$ & $\begin{array}{c}\text { BERAT } \\
\text { EMAS } \\
(\mathrm{mg} / \mathrm{m} 3)\end{array}$ & $\begin{array}{c}\text { JUMLAH } \\
\text { SINABAR } \\
\text { (BUTIR) }\end{array}$ & KETERANGAN \\
\hline 1 & B 39-2/P & Aluvium & 6 & & sungai \\
\hline 2 & B SU5/P & Aluvium & 6000 & & sumur uji \\
\hline 3 & B SU7-1/P & Aluvium & 1320 & & sumur uji \\
\hline 4 & B SU7-2/P & Aluvium & 6 & & sumur uji \\
\hline 5 & B SU8-1/P & Aluvium & 2.6 & & sumur uji \\
\hline 6 & B SU8-2/P & Aluvium & 360 & & sumur uji \\
\hline 7 & B 7/P & Aluvium & 6 & 1 & sungai \\
\hline 8 & B 23/P & Aluvium & 12 & 1 & sungai \\
\hline 9 & B 28-1/P & Aluvium & 82.3 & & sungai \\
\hline 10 & B 28-2/P & Aluvium & 836 & & sungai \\
\hline 11 & B 28-3/P & Aluvium & 33.6 & 1 & sungai \\
\hline 12 & B 31/P & Aluvium & 1244.85 & 2 & sungai \\
\hline 13 & B 36-1/P & Aluvium & 2.6 & & sungai \\
\hline 14 & B 37-1/P & Aluvium & 1391 & 2 & sungai \\
\hline 15 & B 37-2/P & Aluvium & 2026 & 1 & sungai \\
\hline 16 & B 38/P & Aluvium & 781.5 & 1 & sungai \\
\hline 17 & B SU4/P & Aluvium & 22120 & 1 & sumur uji \\
\hline 18 & B 40/P & Aluvium & 14495.5 & 2 & sungai \\
\hline 19 & B 41/P & Aluvium & 1472.1 & 1 & sungai \\
\hline 20 & B 43/P & Aluvium & 5043.1 & 1 & sungai \\
\hline 21 & B 44/P & Aluvium & 367.6 & 19 & sungai \\
\hline 22 & B 45/P & Aluvium & 2.6 & 1 & sungai \\
\hline 23 & B 47/P & Aluvium & 12314.5 & 2 & sungai \\
\hline 24 & B SU1/P & Sekis & 704 & & lereng bukit rendah \\
\hline 25 & B 27-1/P & Sekis & 6 & & lereng bukit rendah \\
\hline 26 & B 27-2/P & Sekis & 2.6 & & lereng bukit rendah \\
\hline 27 & B $27-3 / P$ & Sekis & 13 & & lereng bukit rendah \\
\hline 28 & B 30/P & Sekis & 417 & 1 & lereng bukit rendah \\
\hline 29 & B 42/P & Sekis & 164.05 & 1 & lereng bukit rendah \\
\hline
\end{tabular}

$\mathrm{Au}$ dan 0,5 ppm $\mathrm{Ag}$. Conto batuan lain yang memiliki kadar emas lebih besar adalah B3/R dan B9/R masing-masing $159 \mathrm{ppb}$ dan $172 \mathrm{ppb}$. Conto konsentrat dulang yang mengandung butiran emas seluruhnya berasal dari daerah lereng utara Bukit Tangkeno Wumbubangka dan lembahnya, hasil analisis mineralogi butir (Gambar 6, 7 dan 8) beserta padanan (equivalen) berat butiran emas tercantum pada Tabel 1. Mineral sinabar yang terdapat bersamaan dengan emas dalam konsentrat dulang secara fisik menunjukkan warna merah marun, agak kusam, lunak, bentuk butir lonjong. Pada beberapa conto konsentrat keterdapatan sinabar hanya sebagai jejak di antara mineral-mineral lainnya. Hadirnya sinabar tidak hanya dari conto aluvium saja tetapi juga terdapat dalam konsentrat dulang dari conto batuan sekis teroksidasi.

\section{PEMBAHASAN}

Hasil pengamatan, pengukuran dan pencatatan data di lapangan serta analisis laboratorium dapat diinterpretasikan model keterdapatan emas di lokasi penyelidikan yaitu berupa cebakan emas primer dan endapan emas sekunder.

Kemungkinan terbentuknya cebakan emas primer karena adanya mineralisasi terjadi pada batuan sekis yang dikontrol oleh struktur sesar normal sebagai jalur keluarnya Iarutan 


\section{MAKALAH ILMIAH}

hidrothermal. Sekis dipotong urat-urat kuarsa dan mengalami silisifikasi. Hasil dari analisis mineralogi butir menunjukkan keterdapatan butiran-butiran emas dengan berbagai ukuran yang dinyatakan dengan color (VCC, MC, FC, VFC) seperti pada conto B 37-1/P (Gambar 6) di atas menunjukkan butiran dari sangat kasar sampai sangat halus. Masing-masing butiran memiliki berat equivalen sebagai hasil perkalian banyaknya butiran emas dari conto yang bersangkutan menjadi satuan $\mathrm{mg} / \mathrm{m} 3$ (Tabel 1).

Menurut Prinz dkk, (1978), sinabar memiliki kriteria fisik kekerasan $2-2,5$, berat jenis 8,1 dan mengandung air raksa (mercury) $86,2 \%$, biasanya sinabar ditemukan dalam urat kuarsa yang memotong batu serpentin, gamping, serpih dan macam-macam sekis. Asosiasinya dengan emas, bermacam-macam sulfida terutama pirit dan markasit, kalsit, barit, gipsum, opal dan kuarsa.

Bentuk butir mineral sinabar dan emas sama-sama menyudut hingga membulat tanggung, hal ini mengindikasikan bahwa kedua mineral tersebut masih relatif dekat dengan sumber primernya. Emas dan sinabar terdapat pada urat-urat kuarsa secara bersama-sama sebagai satu kesatuan mineralisasi. Sinabar merupakan mineral petunjuk mineralisasi emas yang terbentuk pada lingkungan temperatur sangat rendah $\left(<200^{\circ} \mathrm{C}\right)$, sehingga dapat diasumsikan bahwa keterjadian emas primer di daerah penyelidikan terjadi pada temperatur

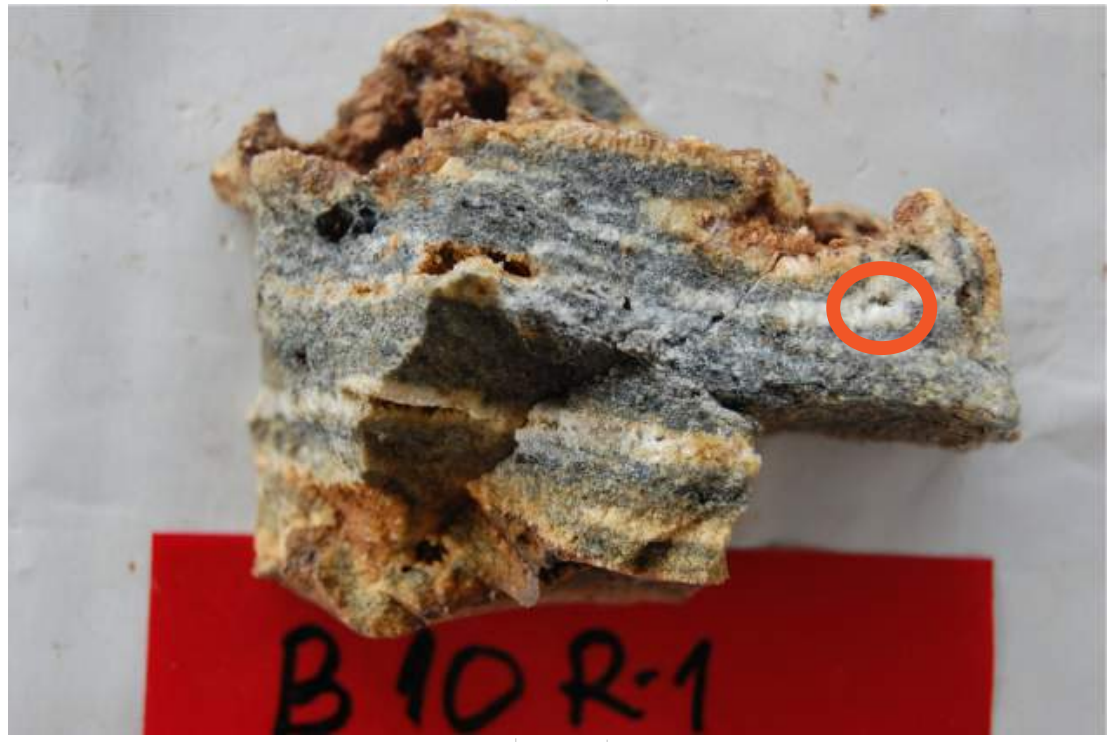

Gambar 9. Conto batuan tersilisifikasi dengan kuarsa vuggy dan dogteeth (lingkaran merah) dalam satuan batuan sekis di Desa Wumbubangka, Kecamatan Rarowatu Utara Kabupaten Bombana (Tim Prospeksi., 2009)

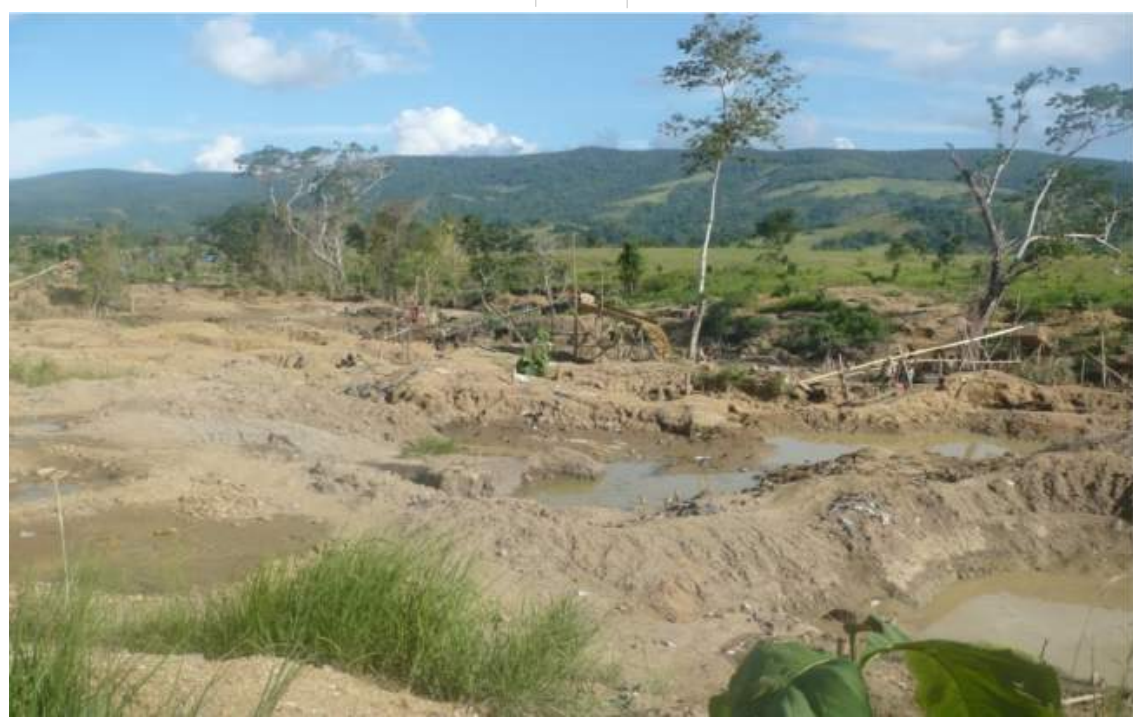

Gambar 10. Lembah alur sungai sebagai tempat diendapkannya aluvial yang mengandung emas di Wumbubangka Kecamatan Rarowatu Utara(Tim Prospeksi, 2009) 


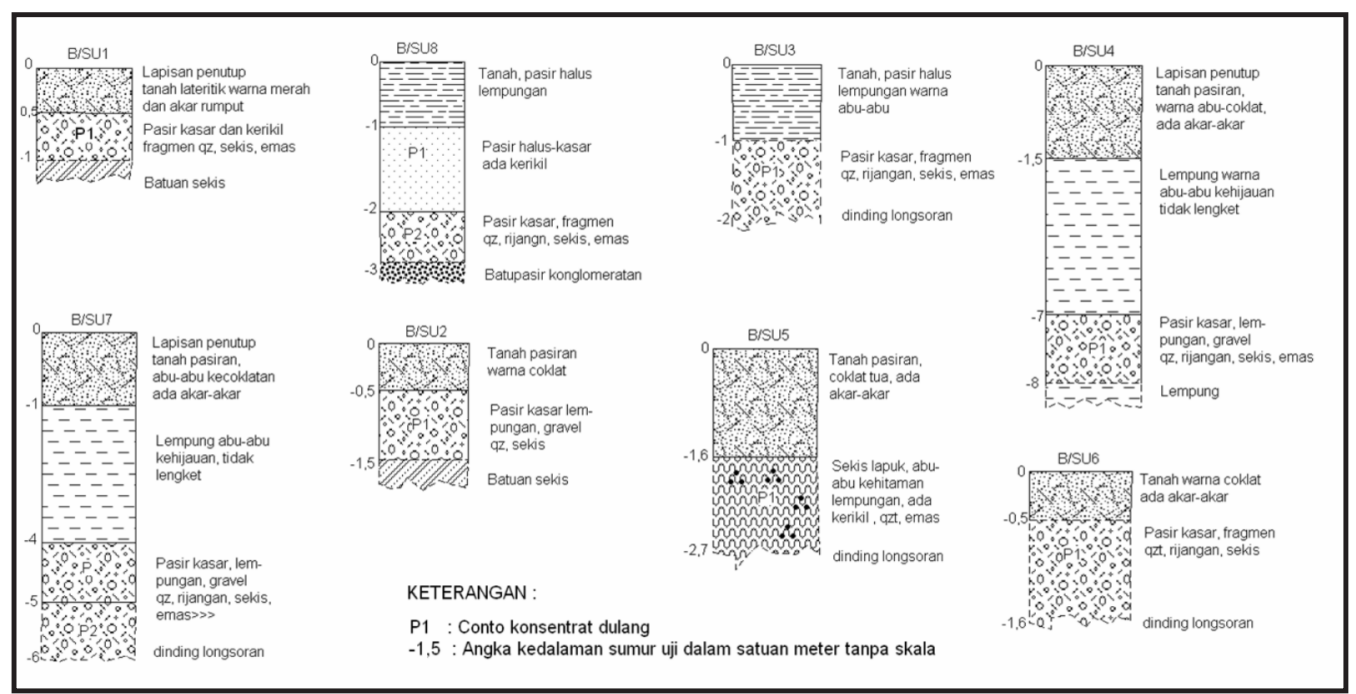

Gambar 11. Sketsa penampang beberapa sumur uji (Tim Prospeksi, 2009)

rendah. Selain itu terdapat mineral-mineral kuarsa yang mengisi rekahan atau ronggarongga yang bertekstur vuggy dan dogteeth. Tekstur kuarsa tersebut umumnya terdapat pada mineralisasi endapan epitermal (Gambar 9).

Di daerah ini juga ditemukan endapan emas sekunder sebagai hasil rombakan material dari satuan batuan sekis teroksidasi dan satuan batupasir konglomeratan. Endapan sekunder ini terdapat pada cekungan-cekungan berupa lembah sepanjang alur-alur sungai yang berhulu di lereng utara Bukit Tangkeno Wumbubangka (Gambar 10). Berdasarkan data sumur uji di sepanjang alur-alur sungai, menunjukkan paling sedikit ada dua kali pengendapan aluvial yang mengandung emas ditutupi oleh lapisan lempung. Lapisan atas secara umum mengandung emas lebih sedikit daripada lapisan di bawahnya dengan ketebalan masing-masing lapisan sangat bervariasi (Gambar 11).

\section{KESIMPULAN}

Keterdapatan emas di daerah penyelidikan terbagi menjadi dua tipe yaitu cebakan emas primer pada batuan sekis teroksidasi dan endapan emas sekunder pada aluvial.

Mineralisasi emas primer tersebut berasosiasi dengan keberadaan sinabar yang menunjukan tipe mineralisasi epitermal bersuhu sangat rendah.

\section{UCAPAN TERIMAKASIH}

Ucapan terima kasih penulis sampaikan kepada Bapak Ir. Bambang Pardiarto, yang telah memberi koreksi dan masukannya. Terima kasih juga kepada tim editor yang telah berkenan memberikan masukan dan koreksinya sehingga makalah ini diterbitkan.

\section{DAFTAR PUSTAKA}

Bagdja, M.P., 1998. Eksplorasi Geokimia Regional, Bersistem Daerah Kabupaten Kendari, dan Kolaka, Sulawesi Tenggara, Direktorat Sumberdaya Mineral, Bandung.

Dinas Pertambangan dan Energi Kabupaten Bombana, 2008, Penyelidikan Geologi Terpadu di Kecamatan Rumbia, Kecamatan Rarowatu Utara, dan Kecamatan Poleang Utara, Dinas Pertambangan dan Energi Kabupaten Bombana.

Tim Prospeksi,2009, Prospeksi Endapan Emas di Daerah Bombana Sulawesi Tenggara, Pusat Sumber Daya Geologi.

Simanjuntak, T.O., Surono dan Sukido, 1993, Peta Geologi Lembar Kolaka, Sulawesi, sekala 1 : 250.000, Pusat Penelitian dan Pengembangan Geologi, Bandung.

Prinz M. , Harlow G.E., Peters J., 1978, Simon and Schuster's guide to rocks and minerals, Simon \& Schuster Inc., New York

Tim Inventarisasi dan Evaluasi, 2005, Inventarisasi dan Evaluasi Sumberdaya Mineral Logam di daerah Kabupaten Bombana dan Kabupaten Muna, Provinsi Sulawesi Tenggara, Direktorat Inventarisasi Sumber Daya Mineral, Bandung.

Naskah diterima tanggal 5 Oktober 2011

Revisi terakhir tanggal 27 September 2011 